\title{
Healthcare Service Payment Methods and Coping Strategies of Nomads and Labor Migrants in Oyo State, Nigeria
}

\author{
Taiwo A. Obembe, ${ }^{1}$ Oluwayomi T. Bankole, ${ }^{2,3 \star}$ Gbolahan Abbas, ${ }^{4}$ and IkeOluwapo O. Ajayi ${ }^{2}$ \\ ${ }^{1}$ Department of Health Policy and Management, University of Ibadan, Ibadan, Nigeria; ${ }^{2}$ Department of Epidemiology and Medical Statistics, \\ University of Ibadan, Ibadan, Nigeria; ${ }^{3}$ Department of Biological Sciences, Elizade University, Ilara-Mokin, Nigeria; ${ }^{4}$ Planning, Research, and \\ Statistics Unit, Oyo State Ministry of Health, Ibadan, Nigeria
}

\begin{abstract}
Nomads and labor migrants constitute a vulnerable group beset with high healthcare costs due to lack of health insurance coverage. Their inability to pay for health care constitutes a threat to their well-being and health risk to the host community as they have higher morbidity from diseases and serve as a reservoir of infective agents. This study investigated how nomads and labor migrants pay and cope with necessary healthcare costs. A cross-sectional study was carried out among 323 migrants in four local government areas of Oyo State, which were selected purposively. A pretested semi-structured questionnaire that sought information on respondents' sociodemographics, healthcare payment methods and coping strategies were employed. Data were analyzed using descriptive statistics and chi-square test to test the association between categorical variables at $P \leq 0.05$. The mean age of the respondents was $34.4 \pm 1.4$ years and $53.2 \%$ were farmers. Of the 200 respondents who had used the formal healthcare system, 13 (6.5\%) obtained free services via the National Health Insurance Scheme (NHIS) and 187 (93.2\%) paid out of pocket for service. Coping with health bills, 115 (62.2\%) paid from savings, 34 (18.4\%) borrowed money, and 58 (31.4\%) sold property. Those with formal education were more likely to pay through NHIS ( $22=9.7, P=0.002)$. Nomads/migrants in this study have demonstrated the inability to cope with payment of health bills, suggesting the need to look into the policy on healthcare funding/support to migrants and educationally disadvantaged persons. The creation of prepaid pooled payment systems such as social and community health insurance schemes is suggested.
\end{abstract}

\section{INTRODUCTION}

The methods of financing healthcare expenditure for any country are vital in determining the health status of the country. ${ }^{1}$ Broadly, consumer payment methods can be grouped into two, namely, pre-service payments and pointof-service payments. Whereas the former usually refers to indirect pooled payments in the form of health insurance schemes, the latter is commonly known as out-of-pocket (OOP) payment. In Nigeria, various health insurance schemes available to healthcare seekers include the National Health Insurance Scheme (NHIS) meant for federal employees, State Health Insurance Scheme (SHIS) for State Government employees, Community-Based Health Insurance Schemes (CBHIS) and Private Health Insurance Scheme (PHIS). ${ }^{2}$ In Nigeria, whereas the NHIS and SHIS health insurance schemes are the most popular payment methods among organized formal sector, ${ }^{3}$ CBHIS is designed for rural dwellers and people in the informal sectors who cannot afford or eligible to get the NHIS, SHIS, or PHIS. ${ }^{2}$ Because very few Nigerians are covered by the health insurance schemes, ${ }^{4}$ the majority at both formal and informal sector including Oyo State still pay for health care at the point-of-service OOP.,

Generally, Nigeria as a middle-income country does not have a universal healthcare plan and, hence, runs both single payer's system where one body, usually the government, collects taxes for the payment of specific health service and multiple payers' system where many approved bodies pool revenues for health insurance of specific and qualified segment of the citizenry. ${ }^{6,7}$ In Nigeria, households provide $70 \%$ of the total health expenditures, and $95 \%$ of these private

*Address correspondence to Oluwayomi T. Bankole, Department of Epidemiology and Medical Statistics, Faculty of Public Health, College of Medicine, University of Ibadan, House 1 Road 9, Moyede-Anifalaje, Akobo, Ibadan, Oyo State 200103, Nigeria. E-mail: bankole.oluwayomi@ gmail.com payments occur via OOP making it the primary method of health financing in the country. ${ }^{8,9}$ Where healthcare payments are made mostly through out-of-pocket expenditure (OOPE), as is the case in Nigeria, inequities abound in access to health care, as only those who can afford to pay can access health services. As such, many households face the risk of not accessing care at all when ill or seeking care from low-level providers, where the quality of care is often low in an effort to avoid debt. ${ }^{10,11}$ It also unleashes a catastrophic financial burden on the poor. ${ }^{3,12}$

Studies show that almost a quarter (24\%) of Nigerian households incur catastrophic health expenditure (CHE), especially in the form of OOPE. ${ }^{13}$ Catastrophic health expenditure is defined as either health expenditures that are equal to or greater than $10 \%$ of total income or health expenditures that sum up to $40 \%$ or greater of a household's non-subsistence income. ${ }^{14}$ This has led to self-medication, untreated morbidity, reduced access to health care, and increased impoverishment among people worse hit by catastrophic payments. ${ }^{15}$ The effect of healthcare payment methods currently used in Nigeria has also been found to vary among population segments. For example, it is probable to reduce the chance of seeking treatment by as much as $71 \%$ in rural areas but only $53 \%$ in urban areas. This implies that residents of rural areas are worse hit by the OOP payment method. ${ }^{16}$

To meet the rising costs of seeking health care, many poor households often resort to coping strategies that are further detrimental to their well-being. These coping mechanisms are responses of the household to the allocation of resources as a result of healthcare costs. ${ }^{17}$ Coping strategies have been defined as "actions intended to maintain household "economic viability" in the face of an economic shock."18 Several studies have documented coping strategies. Although coping mechanisms, for instance, a social network is positive,$^{18}$ others such as borrowing with or without interest, 
selling assets or mortgaging, ${ }^{19,20}$ reduction of essential consumption, ${ }^{21}$ and financial help from relatives ${ }^{22}$ are negative because they lower the socioeconomic status of households involved. These negative coping mechanisms have been found to abound where $\mathrm{CHE}$ is present as households struggle to meet up with the financial demands arising from OOP. ${ }^{23}$

Although migration has always been an activity associated with human existence, its study within the Nigerian context has always focused on the emigration of Nigerians to other countries. However, now more than ever before, a surge in in-country migration is being witnessed. Factors such as the widening North-South divide, political tensions, and the "Boko Haram" insurgency in the North have increased waves of migration to southwestern states of the country. Most of these migrants are nomads who take advantage of the agricultural setup in the Southwest region. ${ }^{24}$ This surge in migration has led to increased attention and concern about the health care of such migrants. Because health is a social good, poor health status among this population segment could negatively impact on the health status of the general population. ${ }^{25}$ Also, migrants are usually exposed to factors such as the absence of social amenities, over-crowding, poor access to healthcare facilities and access to social insurance which can worsen their health status. ${ }^{26}$ Thus, it becomes important to understand how nomads and labor migrants' population pay for health care and how they cope with such payments. Thus, this study aimed at determining the payment methods and coping strategies of nomads and labor migrants in Oyo State.

\section{METHODS}

Study setting. The study was implemented in Oyo State, which was created in 1976. It is in Southwest Nigeria and has Ibadan as the state capital. The State comprises 33 local governments. Oyo state is bounded by four other states: to the North (Kwara State), South (Ogun State), East (Osun State), and to the West partly by Ogun State and partly by the Republic of Benin. ${ }^{27}$ Oyo State is homogenous, mostly inhabited by the "Yorubas" who are predominantly farmers. ${ }^{28}$ However, migrants are concentrated on the border local governments. According to Oyo State Government Strategic Health Development Plan (2010-2015), all the three levels of care (i.e., Primary, Secondary, and Tertiary) are appreciably distributed across the State with about 1,560 health facilities (public and private) present. To a reasonable extent, these large numbers of health facilities have a positive impact on health service coverage in the State. However, there are still vast areas of the State that are still underserved by the present health facility distribution. Majorly, people pay for health services in the state via the OOP method, although the state has social health insurance. ${ }^{5}$

Study design. The research used a cross-sectional design to determine the health service payment methods and coping strategies of nomads and labor migrants in four selected border local governments' areas of Oyo State between October and November 2016.

Sampling and sample size. The sample size for the study was calculated using the formula.

$$
n=\left[Z^{2} P(1-P)\right] / d^{2}
$$

where $Z_{\alpha / 2}$ at type I error of $5 \%=1.96, P=26 \%$, and $d=5 \% .^{17}$

Substituting the values in the formula gave the " $n$ " value of 296. Considering a $10 \%$ nonresponse rate, the minimum sample size " $n$ " was approximated as 326 . Of 326,323 were valid. Nonvalid ones were excluded from the analysis.

Four border local governments' areas of Oyo State were purposively selected for this study because of the concentration of migrants' settlements. Within each local government area (LGA), the one ward where many of the migrants were concentrated was selected. Within each selected ward, the community harboring most of the migrants was studied. The sample size was allocated proportionately to the size of the communities. The interview was conducted from house to house until the allocated number of respondents for each community was obtained. The direction to choose the first house to start was determined by tossing a coin standing at the center of the community's marketplace. The interview was carried out among household heads; and in a situation in which the head has not resided in the community for at least 1 year, an adult aged 18 years and older was interviewed. Where there are more adults greater than or 18 years old, balloting was performed to choose one to interview.

Data collection. A semi-structured, interviewer-administered questionnaire was used to collect the data. The questionnaire contained questions on sociodemographic characteristics of the respondents, interaction with the formal healthcare sector, healthcare service payment methods, and coping strategies. The questionnaire was translated into Yoruba Language and back-translated into the English Language by an independent translator to ensure accuracy. The data collection tool was pretested among migrants in Saki East and Iseyin local government. The interviewers recruited for the study were trained at a 2-day training session on the administration of the questionnaire using question-and-answer sessions, lectures, and role-plays. Interviewers recruited had completed some form of post-secondary education. The interview was conducted in a secluded area in the house at a time convenient for the respondents.

Data analysis. Analysis was carried out using Statistical Package for Social Sciences software version 21. Data collected were analyzed using descriptive statistics such as frequency and percentages. A chi-square test was used as an inferential statistical tool to test the association between categorical independent and dependent variables. Binary logistic regression was carried out to control for confounders. Statistically significant associations were recorded at $\leq 5 \%$.

Ethical consideration. Ethical approval for this study was obtained from the Oyo State Ministry of Health Institutional Review Board before the commencement of the study. Only eligible participants who willingly signed informed consent forms after being satisfactorily briefed about the study participated in the study. Data collected included no identifiers that could be used to link individual questionnaires to specific respondents. All data were kept confidential on a passwordprotected computer to which only the investigators had access to.

Inclusion and exclusion criteria. Migrants aged 18 years and older met in the settlements/communities on the day of the interview were included, whereas non-consenting respondents were excluded from the study. 
Study limitations. Migrants younger than 18 years who have not lived in the community for at least 1 year were not covered in the survey.

\section{RESULTS}

About half $(179 ; 55.4 \%)$ of the respondents were men. The mean age of the respondent was $34.37 \pm 1.42$ years. More than one-fourth $(87 ; 26.9 \%)$ of respondents were between the age group of $30-39$ years. Almost half $(158 ; 48.9 \%)$ of respondents were from the Benin Republic, whereas Nigerian migrants constitute 135 (41.8\%) of the respondents. Sixty-two percent of the respondents had not completed any form of formal education, and farming $172(53.2 \%)$ was the most common occupation among the respondents (Table 1).

More men (106; 53.0\%) than women $(94 ; 47.0 \%)$ had ever visited a formal healthcare facility $(P=0.27)$. Respondents within the age group of 30-39 years were the most (56; $28.0 \%)$ among respondents who had ever used the formal healthcare system. Among those who had never used a formal healthcare facility, respondents in the age group 21-29 years constituted the majority $(35 ; 28.5 \%)$. A significantly higher proportion of respondents from the neighboring country (Benin Republic) (106; 53.0\%) had accessed a healthcare facility before compared with Nigerians $(83 ; 41.5 \%, P=0.007)$. Almost two-thirds of respondents with no education $(125 ; 62.5 \%)$ compared with educated counterparts 75 (37.5\%) had used the formal healthcare system $(P=0.78)$ (Table 2$)$.

TABLE 1

Sociodemographic characteristics of the respondents $(N=323)$

\begin{tabular}{|c|c|}
\hline Characteristics & $N \%$ \\
\hline \multicolumn{2}{|l|}{ Gender } \\
\hline Male & $179(55.4)$ \\
\hline Female & $144(44.6)$ \\
\hline \multicolumn{2}{|l|}{ Age group (years) } \\
\hline$\leq 20$ & $58(18.0)$ \\
\hline $21-29$ & 71 (22.0) \\
\hline 30-39 & 87 (26.9) \\
\hline $40-49$ & $57(17.6)$ \\
\hline$>50$ & $50(15.5)$ \\
\hline \multicolumn{2}{|l|}{ Nationality } \\
\hline Benin Republic & $158(48.9)$ \\
\hline Nigerian & $135(41.8)$ \\
\hline Other & $30(9.3)$ \\
\hline \multicolumn{2}{|l|}{ Religion } \\
\hline Islam & $189(58.5)$ \\
\hline Christianity & $134(41.5)$ \\
\hline \multicolumn{2}{|l|}{ Marital status } \\
\hline Ever married & $263(81.4)$ \\
\hline Single & $60(18.6)$ \\
\hline \multicolumn{2}{|l|}{ Educational status } \\
\hline No formal education & $200(61.9)$ \\
\hline Formal education† & $123(38.1)$ \\
\hline \multicolumn{2}{|l|}{ Main occupation } \\
\hline Farming & $172(53.2)$ \\
\hline Trading & $68(21.1)$ \\
\hline Artisan & $33(10.2$ \\
\hline Other & $20(6.2)$ \\
\hline Unemployed & $17(5.3)$ \\
\hline Mining & $13(4.0)$ \\
\hline \multicolumn{2}{|l|}{ Average monthly income } \\
\hline$\leq \notin 10,000^{\star}$ & $174(53.9)$ \\
\hline$>10,000^{\star}$ & $149(46.1)$ \\
\hline
\end{tabular}

† Has completed at least primary education.
A logistic regression analysis was carried out to ascertain the effects of gender, age, nationality, religion, marital status, educational status, and average monthly income on the likelihood that respondents will use healthcare service. Only the nationality of the respondents added significantly to the logistic regression model. Respondents from other nationalities aside from the Benin Republic were 2.77 times more likely not to use the healthcare service than Nigerians do. Increasing the income was associated with an increased likelihood that respondents will use the healthcare service (Table 3).

Among respondents who had used the formal healthcare system, 15 (7.5\%) obtained free services via the NHIS, whereas the remaining $185(92.5 \%)$ paid cash OOP. More men $(95 ; 51.4 \%)$ than women $(90 ; 48.6 \%)$ paid for health care via OOP $(P=0.10)$. Similarly, no statistical association was found between payment method and age group, nationality, religion, marital status, and average monthly. More respondents earning less than 10,000 accessed health care through the NHIS than those earning more than $10,000(P=$ 0.93). Education played a statistically significant role in determining those who obtained care via NHIS coverage and those who did not. Respondents with some form of education $(10 ; 66.7 \%)$ accessed health care through the NHIS compared with those $(5 ; 33.3 \%)$ with no formal education $(P=0.02)$ (Table 4).

The gender, age, nationality, religion, marital status, educational status, and average monthly income of respondents were also used to predict the method of health service payment. In the binary logistic regression model, only the educational status of the respondents was independently associated with the method of health service payment. Respondents from other nationality, excluding the respondents from the Benin Republic, were 0.44 times less likely to pay cash or OOP (Table 5).

Analysis of the respondents who paid cash showed that about equal proportions of both men $(58 ; 50.4 \%)$ and women $(57 ; 49.6 \%)$ used their savings to cope with their healthcare payments and the same proportion of women (29; $50.0 \%)$ and men $(29 ; 50.0 \%)$ sold property. Also, respondents aged $30-39$ years $(35 ; 39.4 \%)$ formed the age group with the highest number of respondents who used savings, whereas those aged $30-39$ years and 50 years and older were the highest proportion 9 (26.5\%) of respondents who borrowed to cope with healthcare payments. Whereas $5(14.7 \%)$ and $5(8.6 \%)$ of other nationalities borrowed and sold property, respectively, to cope with the health service payment, more than half $(69 ; 60.0 \%)$ of the respondents from the Benin Republic used savings. The proportion of ever-married (92; $80.0 \%$ ) respondents who used their savings to offset healthcare bills was far more than those who were single 23 $(20.0 \%)$. Among participants with no formal education, more than twice the proportion of formally educated respondents $(37 ; 32.2 \%)$ used savings to cope with healthcare payments (Table 6).

The proportion of respondents who were aware and enrolled for NHIS was also investigated. Almost equal proportion of women $(16 ; 48.5 \%)$ and men $(17 ; 51.9 \%)$ were aware of NHIS. Among those who were aware, only 7 (53.8\%) men and 6 (46.2\%) women were enrolled. Respondents aged $\leq 20$ years had the highest enrollment (5; $38.5 \%)$. Other nationalities aside Republic of Benin and 
TABLE 2

Association between sociodemographic characteristics and healthcare utilization among respondents $(N=323)$

\begin{tabular}{|c|c|c|c|c|}
\hline \multirow[b]{2}{*}{ Characteristics } & \multirow{2}{*}{$\frac{\text { Ever used formal health care }(n=200)}{n(\%)}$} & \multicolumn{3}{|l|}{ Never used formal health care $(n=123)$} \\
\hline & & $n(\%)$ & $x^{2}$ & $P$-value \\
\hline \multicolumn{5}{|l|}{ Gender } \\
\hline Male & $106(53.0)$ & $73(59.4)$ & 1.24 & 0.27 \\
\hline Female & $94(47.0)$ & $50(40.6)$ & & \\
\hline \multicolumn{5}{|l|}{ Age Group (years) } \\
\hline$\leq 20$ & $37(18.5)$ & $21(17.0)$ & 5.09 & 0.28 \\
\hline $21-29$ & 36 (18.0) & 35 (28.5) & & \\
\hline $30-39$ & $56(28.0)$ & 31 (25.2) & & \\
\hline $40-49$ & 37 (18.7) & $20(16.3)$ & & \\
\hline$>50$ & $34(17.0)$ & $16(13.0)$ & & \\
\hline \multicolumn{5}{|l|}{ Nationality } \\
\hline Benin Republic & $106(53.0)$ & $52(42.3)$ & 9.915 & $0.007^{\star}$ \\
\hline Nigerian & $83(41.5)$ & $52(42.3)$ & & \\
\hline Other & $11(5.5)$ & $19(15.4)$ & & \\
\hline \multicolumn{5}{|l|}{ Religion } \\
\hline Islam & $121(60.5)$ & $68(55.3)$ & 0.85 & 0.36 \\
\hline Christianity & 79 (39.5) & $55(44.7)$ & & \\
\hline \multicolumn{5}{|l|}{ Marital status } \\
\hline Ever married & $167(83.5)$ & $96(78.1)$ & 1.50 & 0.22 \\
\hline Single & 33 (16.5) & 27 (21.9) & & \\
\hline \multicolumn{5}{|l|}{ Educational status } \\
\hline No formal education & $125(62.5)$ & $75(61.0)$ & 0.08 & 0.78 \\
\hline Formal education & $75(37.5)$ & $48(39.0)$ & & \\
\hline \multicolumn{5}{|l|}{ Average monthly income } \\
\hline$\leq \notin 10,000$ & $109(54.5)$ & $65(52.8)$ & 0.08 & 0.77 \\
\hline$>10,000$ & $91(45.5)$ & $58(47.2)$ & & \\
\hline
\end{tabular}

Nigeria reported no enrollment despite some degree of awareness (Table 5). Also evident was the influence of the income of nomads on enrollment. More nomads $(7 ; 53 \%)$ earning more than 10,000 were enrolled in the NHIS compared with $6(46.2 \%)$ of the respondents with income less than 10,000 (Table 7).

\section{DISCUSSION}

The healthcare payment methods of the citizenry have been found to correlate with the health status of the populace and in the end, the economy of the country. Whereas certain payment methods such as social insurance and other prepaid methods have been found to encourage the use of formal healthcare system, other methods such as OOPE has been found to negatively impact the health-seeking behavior of citizens. Out-of-pocket expenditure has also been implicated in negative coping strategies such as borrowing and selling of properties.

TABLE 3

Predictors of healthcare utilization among respondents $(N=200)$

\begin{tabular}{lcccccc}
\hline & & & & \multicolumn{2}{c}{$95 \% \mathrm{Cl}$ for OR } \\
\cline { 5 - 7 } \multicolumn{1}{c}{ Characteristics } & $\mathrm{x}^{2}$ & $P$-value & OR & Lower & Upper \\
\hline Gender & 0.66 & 0.42 & 0.81 & 0.49 & 1.34 \\
Age (years) & 1.83 & 0.18 & 0.88 & 0.72 & 1.06 \\
Nationality (others) & 5.76 & $0.02^{*}$ & 2.77 & 1.21 & 6.37 \\
Religion & 0.50 & 0.48 & 0.84 & 0.52 & 1.35 \\
Marital status & 0.72 & 0.40 & 1.32 & 0.69 & 2.52 \\
Educational status & 0.40 & 0.53 & 0.84 & 0.50 & 1.42 \\
Average monthly income & 0.07 & 0.79 & 1.07 & 0.66 & 1.71 \\
\hline The logistic regression model reported in this table controls for the listed characteristics. \\
* Significant at 5\%.
\end{tabular}

This study investigated how migrants in selected LGAs of Oyo State pay for healthcare service and the coping strategies used to service the payment. The sociodemographic data showed that respondents from the Benin Republic were the most migrants. This could be related to the geographical proximity of the country to the borders of Oyo State, thus making migration into Oyo State, especially the northern axis, easier for the residents in that country. ${ }^{29,30}$ The fact that just a little over a third of the respondents had completed any form of formal education further highlights the low literacy level usually observed among migrants. Studies have shown that most African migrants are from the lower socioeconomic status, probably as a result of not being properly educated, a situation further worsened by the inequitable provision of educational facilities in areas where they settle. ${ }^{31,32}$ The low socioeconomic status of the respondents is also demonstrated by the fact that more than half of the respondents earned less than a dollar a day.

The results also showed that a higher proportion of men than women had used the formal healthcare system. This is probably due to the increased awareness and positive health-seeking behavior among men, which have made them more conscious of their health status as opposed to the African culture which expects men to be strong and healthy. ${ }^{33}$ As such, they are not likely to use formal healthcare systems until their illness is quite pronounced. Another factor to consider is the proximity of the health center to the migrant community. Whereas women may not have the required strength to walk to a distant health center to seek health care, men are naturally stronger and could go further to seek health care. Concerning payment methods of those who used the formal healthcare system, the fact that a clear majority used OOP payment is not surprising as the method remains the 
TABLE 4

Association between healthcare service payment methods and sociodemographic characteristics of respondents $(N=200)$

\begin{tabular}{|c|c|c|c|c|}
\hline \multirow[b]{2}{*}{ Characteristics } & \multirow{2}{*}{$\begin{array}{c}\begin{array}{c}\text { National Health Insurance } \\
\text { Scheme }(n=15)\end{array} \\
n(\%)\end{array}$} & \multirow{2}{*}{$\frac{\text { Out-of-pocket }(n=185)}{n(\%)}$} & \multirow[b]{2}{*}{$x^{2}$} & \multirow[b]{2}{*}{$P$-value } \\
\hline & & & & \\
\hline \multicolumn{5}{|l|}{ Gender } \\
\hline Male & $11(73.3)$ & $95(51.4)$ & \multirow[t]{2}{*}{2.69} & \multirow[t]{2}{*}{0.10} \\
\hline Female & $4(26.7)$ & $90(48.6)$ & & \\
\hline \multicolumn{5}{|l|}{ Age group (years) } \\
\hline$\leq 20$ & $1(6.7)$ & $36(19.5)$ & \multirow[t]{5}{*}{$4.27^{\star}$} & \multirow[t]{5}{*}{0.37} \\
\hline $21-29$ & $1(6.7)$ & 35 (18.9) & & \\
\hline $30-39$ & $5(33.3)$ & $51(27.6)$ & & \\
\hline $40-49$ & $5(33.3)$ & $32(17.3)$ & & \\
\hline$>50$ & $3(20.0)$ & $31(16.8)$ & & \\
\hline \multicolumn{5}{|l|}{ Nationality } \\
\hline Nigerian & $8(53.3)$ & 75 (40.5) & \multirow[t]{3}{*}{$3.54^{*}$} & \multirow[t]{3}{*}{0.17} \\
\hline Benin Republic & $5(33.3)$ & $101(54.6)$ & & \\
\hline Other & $2(13.3)$ & $9(4.9)$ & & \\
\hline \multicolumn{5}{|l|}{ Religion } \\
\hline Christianity & $7(46.7)$ & 72 (38.9) & \multirow[t]{2}{*}{0.35} & \multirow[t]{2}{*}{0.56} \\
\hline Islam & $8(53.3)$ & $113(61.1)$ & & \\
\hline \multicolumn{5}{|l|}{ Marital status } \\
\hline Ever married & $13(86.7)$ & 154 (83.2) & \multirow[t]{2}{*}{0.12} & \multirow[t]{2}{*}{0.73} \\
\hline Single & $2(13.3)$ & $31(16.8)$ & & \\
\hline \multicolumn{5}{|l|}{ Educational status } \\
\hline No formal education & 5 (33.3) & $120(64.9)$ & \multirow[t]{2}{*}{5.89} & \multirow[t]{2}{*}{$0.02 \dagger$} \\
\hline Formal education & $10(66.7)$ & $65(35.1)$ & & \\
\hline \multicolumn{5}{|l|}{ Average monthly income } \\
\hline$\leq \notin 10,000$ & 8 (53.3) & $101(54.6)$ & \multirow[t]{2}{*}{0.009} & \multirow[t]{2}{*}{0.93} \\
\hline$>\# 10,000$ & $7(46.7)$ & $84(45.4)$ & & \\
\hline
\end{tabular}

most popular payment method in Nigeria. ${ }^{18}$ However, the proportion recorded among the migrant population is higher than those observed among other population segments are. The increased likelihood of educated people to access information about NHIS, to understand the information, and act on it has been documented by other studies. ${ }^{34,35}$ The results of this study indicate that the same trend may be true among the migrant population. Notably, in terms of awareness and enrolment in the NHIS, respondents from Benin Republic were more than those from Nigeria. This outcome suggests that Benin Republic nationals who participated in the study perceived some level of benefits in the NHIS than respondents from Nigeria and other nationals, and thus, they decided to enroll.

Using savings to pay for health care was the most reported coping strategy among the respondents. Incomes have been reported as common coping mechanisms in other African low- and middle-income countries (LMICs) such as Zambia, Cote d'Ivoire, and Chad. ${ }^{19,36}$ However, it has been noted that

TABLE 5

Predictors of health service payment methods (National Health Insurance Scheme and out-of-pocket) among respondents $(N=200)$

\begin{tabular}{lcccccc}
\hline \multirow{2}{*}{ Characteristics } & & & & \multicolumn{2}{c}{$95 \% \mathrm{Cl}$ for OR } \\
\cline { 5 - 7 } & $\mathrm{x}^{2}$ & P-value & OR & Lower & Upper \\
\hline Gender & 1.97 & 0.16 & 2.55 & 0.69 & 9.45 \\
Age & 1.72 & 0.19 & 0.72 & 0.44 & 1.18 \\
Nationality (others) & 0.38 & 0.54 & 0.56 & 0.09 & 3.56 \\
Religion & 0.03 & 0.87 & 1.10 & 0.33 & 3.69 \\
Marital status & 0.31 & 0.58 & 1.64 & 0.29 & 9.32 \\
Educational status & 4.88 & $0.03^{*}$ & 0.22 & 0.06 & 0.85 \\
Average monthly income & 0.85 & 0.38 & 1.73 & 0.54 & 5.60 \\
\hline${ }^{*}$ Significant at 5\%. & & & & &
\end{tabular}

when households use savings meant for other essential purposes, such as food and shelter, as coping mechanisms, it jeopardizes the future health of the household and could lead to further impoverishment. ${ }^{36,37}$ Selling property is another popular coping mechanism noticed in LMICs, although other studies have noticed it albeit among wealthier groups. ${ }^{38}$ Similarly, in this study, selling the property to cope with healthcare costs was more popular among respondents earning more than a dollar daily than their counterparts earning less than a dollar daily. It could also mean that very few options of what to sell were available for those earning less than a dollar per day. More than one in every five respondents who used OOP payment had to borrow to cope with the healthcare cost. Within the African context, borrowing is often done from professional money lenders who charge exorbitant interest rates, with reported rates ranging from $5 \%$ to as much as $30 \% .{ }^{18,39}$ This means that households have an even greater debt after coping with the OOP. In addition, accumulated debts can result into worse economic and social status of households if not repaid quickly. ${ }^{40,41}$

The findings of our study should be interpreted aptly while bearing the following limitations in mind. As with all other cross-sectional surveys, our research can explain associated factors with healthcare utilization and choice of payment for healthcare services, but it cannot establish temporality or causation. Our study could have yielded more robust findings if a qualitative study (sequential explanatory design precisely) had been carried out to probe the reasons for the different levels of utilization and variations in payment methods among the participants. Qualitative studies and triangulation of findings should be undertaken in subsequent studies to establish a deeper understanding of the factors influencing such variations in the outcome of interest. The generalization of our 
TABLE 6

Coping strategies of out-of-pocket users across sociodemographic characteristics $(N=185)$

\begin{tabular}{|c|c|c|c|c|c|c|c|c|c|}
\hline \multirow[b]{2}{*}{ Characteristics } & \multicolumn{3}{|c|}{ Savings $^{*}(N=115)$} & \multicolumn{3}{|c|}{ Borrowing* $(N=34)$} & \multicolumn{3}{|c|}{ Sale of property* $(N=58)$} \\
\hline & $n(\%)$ & $x^{2}$ & $P$-value & $n(\%)$ & $x^{2}$ & $P$-value & $n(\%)$ & $x^{2}$ & $P$-value \\
\hline \multicolumn{10}{|l|}{ Gender } \\
\hline Male & $58(50.4)$ & 0.10 & 0.75 & $18(52.9)$ & 0.04 & 0.84 & $29(50.0)$ & 0.06 & 0.80 \\
\hline Female & 57 (49.6) & & & $16(47.1)$ & & & 29 (50.0) & & \\
\hline \multicolumn{10}{|l|}{ Age group (years) } \\
\hline$\leq 20$ & 26 (22.6) & 3.59 & 0.46 & $4(11.8)$ & 5.70 & 0.22 & $9(15.5)$ & 5.34 & 0.25 \\
\hline $21-29$ & $23(20.0)$ & & & $4(11.8)$ & & & $11(19.0)$ & & \\
\hline $30-39$ & 27 (23.5) & & & $9(26.5)$ & & & $22(37.9)$ & & \\
\hline $40-49$ & $20(17.4)$ & & & $8(23.5)$ & & & 7 (12.1) & & \\
\hline$>50$ & $19(16.5)$ & & & $9(26.5)$ & & & $9(15.5)$ & & \\
\hline \multicolumn{10}{|l|}{ Nationality } \\
\hline Nigerian & $43(37.4)$ & 5.55 & 0.06 & $15(44.1)$ & 9.80 & 0.007 & $26(44.8)$ & 3.83 & 0.15 \\
\hline Benin Republic & 69 (60.0) & & & $14(41.2)$ & & & 27 (46.6) & & \\
\hline Other & $3(2.6)$ & & & $5(14.7)$ & & & $5(8.6)$ & & \\
\hline \multicolumn{10}{|l|}{ Religion } \\
\hline Islam & 65 (56.5) & 2.66 & 0.10 & $20(58.8)$ & 0.09 & 0.77 & $38(65.5)$ & 0.70 & 0.40 \\
\hline Christianity & $50(43.5)$ & & & 14 (41.2) & & & $20(34.5)$ & & \\
\hline \multicolumn{10}{|l|}{ Marital status } \\
\hline Ever married & $92(80.0)$ & 2.29 & 0.13 & 30 (88.2) & 0.74 & 0.39 & $52(89.7)$ & 2.50 & 0.11 \\
\hline Single & $23(20.0)$ & & & $4(11.8)$ & & & 6 (10.3) & & \\
\hline \multicolumn{10}{|l|}{ Educational status } \\
\hline No formal education & $78(67.8)$ & $1.16^{\prime}$ & 0.28 & $20(58.8)$ & 0.67 & 0.41 & $35(60.3)$ & 0.76 & 0.38 \\
\hline Formal education & 37 (32.2) & & & $14(41.2)$ & & & $23(39.7)$ & & \\
\hline \multicolumn{10}{|l|}{ Average monthly income } \\
\hline 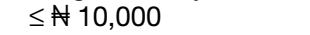 & $69(60.0)$ & 3.58 & 0.058 & $13(38.2)$ & 4.50 & 0.03 & $28(48.3)$ & 1.36 & 0.24 \\
\hline$>\# 10,000$ & $46(40.0)$ & & & $21(61.8)$ & & & $30(51.7)$ & & \\
\hline
\end{tabular}

results is limited because of the location chosen for the selection of our participants.

\section{CONCLUSION}

This study highlighted the high exposure of migrants to OOPE for health care and its indirect effects, such as engagement in negative coping mechanisms like borrowing, depleting savings, and selling properties. To prevent the negative health and economic consequences that could arise from the situation, policymakers need to review the created prepaid pooled payment systems such as social and community-based insurance schemes among this population. This review should include the enrollment criteria in a way to encourage more migrants to register for the schemes. Creating additional social protection programs, which may

TABLE 7

Awareness and enrollment in the NHIS by sociodemographic characteristics of respondents $(N=46)$

\begin{tabular}{lcc}
\hline \multicolumn{1}{c}{ Characteristics } & Aware of NHIS $(N=33), n(\%)$ & Aware and enrolled in NHIS $(N=13), n(\%)$ \\
\hline Gender & & $7(53.8)$ \\
Male & $17(51.5)$ & $6(46.2)$ \\
Female & $16(48.5)$ & $5(38.5)$ \\
Age group & & $3(23.0)$ \\
20 and younger & $8(24.2)$ & $2(15.4)$ \\
$21-29$ & $3(9.1)$ & $2(15.4)$ \\
$30-39$ & $7(21.2)$ & $1(7.7)$ \\
$40-49$ & $11(33.3)$ & $9(69.2)$ \\
50 and older & $4(12.1)$ & $4(30.8)$ \\
Nationality & $17(51.5)$ & $0(0.0)$ \\
Benin Republic & $12(36.4)$ & $6(46.2)$ \\
Nigerian & $4(12.1)$ & $7(53.8)$ \\
Other & $14(42.4)$ & $6(46.2)$ \\
Religion & $19(57.6)$ & $7(53.8)$ \\
Christianity & & \\
Islam & $25(75.8)$ & $4(30.8)$ \\
Marital status & $8(24.2)$ & $9(69.2)$ \\
Currently married & & \\
Currently single & $16(48.5)$ & $6(46.2)$ \\
Highest educational level attained & $17(51.5)$ & $7(53.8)$ \\
No formal education & $16(48.5)$ & \\
Formally educated & $17(51.5)$ & \\
Average monthly income & & \\
S 10,000 & & \\
> 10,000 & &
\end{tabular}


include waivers and exemptions for the poor and vulnerable, is advised.

Received July 26, 2018. Accepted for publication January 31, 2020.

Published online March 30, 2020.

Acknowledgments: We thank all the nomads and labor migrants who volunteered to participate in the study. We also appreciate Olajimi Latunji for his contributions. The American Society of Tropical Medicine and Hygiene (ASTMH) assisted with publication expenses.

Financial support: We appreciate the funding support from the World Health Organization. This investigation received financial support from The African Regional Office of the World Health Organization (WHO/AFRO) and the Special Programme for Research and Training in Tropical Diseases (TDR): AFRO/TDR Small Grants Scheme for Implementation Research in Infectious Diseases of Poverty in Africa.

Disclaimer: The conduct of this study and findings are exclusively those of the authors and not in any way represent the views of the funders.

Authors' addresses: Taiwo A. Obembe, Department of Health Policy and Management, Faculty of Public Health, College of Medicine, University of Ibadan, Ibadan, Nigeria, E-mail: tobems@yahoo.com. Oluwayomi T. Bankole and IkeOluwapo O. Ajayi, Department of Epidemiology and Medical Statistics, Faculty of Public Health, College of Medicine, University of Ibadan, Ibadan, Nigeria, E-mails: bankole. oluwayomi@gmail.com and ikeajayi2003@yahoo.com. Gbolahan Abbass, Department of Planning, Research and Statistics, Oyo State Ministry of Health, Ibadan, Nigeria, E-mail: gbolaabass@ yahoo.com.

\section{REFERENCES}

1. Olakunde BO, 2012. Public health care financing in Nigeria: which way forward? Ann Niger Med 6: 4.

2. Uzochukwu BS, Ughasoro MD, Etiaba E, Okwuosa C, Envuladu E, Onwujekwe OE, 2015. Health care financing in Nigeria: implications for achieving universal health coverage. Niger $J$ Clin Pract 18: 437-444.

3. Onoka CA, Onwujekwe OE, Uzochukwu BS, Ezumah NN, 2013. Promoting universal financial protection: constraints and enabling factors in scaling-up coverage with social health insurance in Nigeria. Heal Res Pol Syst 11: 20.

4. Aregbeshola BS, 2016. Out-of-pocket payments in Nigeria. Lancet 387: 2506 .

5. Adewole DA, Adebayo AM, Udeh El, Shaahu VN, Dairo MD, 2015. Payment for health care and perception of the national health insurance scheme in a rural area in Southwest Nigeria. Am J Trop Med Hyg 93: 648-654.

6. Osibogun A, 2018. Politics and Health: implications of the nexus to the Nigerian citizen. In Maiden Annual Public Lecture, Medical and Dental Consultants Association of Nigeria, Presented, 15th November 2018, Chelsea Hotel, Abuja, Nigeria.

7. Hussey P, Anderson GF, 2003. A comparison of single-and multipayer health insurance systems and options for reform. Health Pol 66: 215-228.

8. Ukwaja KN, Hopewell PC, Abimbola S, Alobu I, 2013. Household catastrophic payments for tuberculosis care in Nigeria: incidence, determinants, and policy implications for universal health coverage. Infect Dis Poverty 2: 21.

9. Uzochukwu BSC, Ughasoro MD, Etiaba E, Okwuosa C, Envuladu E, Onwujekwe OE, 2015. Health care financing in Nigeria: implications for achieving universal health coverage. Nigerian Journal of Clinical Practice 18: 437-444.

10. Chuma J, Maina T, 2012. Catastrophic health care spending and impoverishment in Kenya. BMC Health Serv Res 12: 413.

11. Riman HB, Akpan ES, 2012. Healthcare financing and health outcomes in Nigeria: A state-level study using multivariate analysis. Int. J. Hum. Soc. Sci 2: 296-309.

12. Onah MN, Govender V, 2014. Out-of-pocket payments, health care access and utilization in south-eastern Nigeria: a gender perspective. PLoS One 9: e93887.
13. Amakom U, Ezenekwe U, 2012. Implications of households catastrophic out of pocket (OOP) healthcare spending in Nigeria. $J$ Res Econ Int Financ. 1: 136-140.

14. Puteh SE, Almualm Y, 2017. Catastrophic health expenditure among developing countries. Health Syst Pol Res 4: 1.

15. Ataguba J, Ichoku EH, Fonta W, Okpanachi A, Okon U, 2006. An estimation of the willingness to pay for community healthcare risk-sharing prepayment scheme and the medical poverty trap: evidence from rural Nigeria. In 5th poverty and economic policy $(P E P)$ research network general meeting. South Africa: University of Cape Town.

16. Amakom U, Ezenekwe U, 2012. Implications of households catastrophic out of pocket (OOP) healthcare spending in Nigeria. Journal of Research in Economics and International Finance 1: 136-140.

17. Ewelukwa O, Onoka $\mathrm{C}$, Onwujekwe $\mathrm{O}, 2013$. Viewing health expenditures, payment and coping mechanisms with an equity lens in Nigeria. BMC Health Serv Res 13: 87.

18. Onwujekwe OE, Uzochukwu BSC, Obikeze EN, Okoronkwo I, Ochonma OG, Onoka CA, 2010. Investigating determinants of out-of-pocket spending and strategies for coping with payments for healthcare in southeast Nigeria. BMC Health Serv Res 10: 67.

19. Leive A, Xu K, 2008. Coping with out-of-pocket health payments: empirical evidence from African countries. Bull World Health Organ 86: 849-856.

20. Alamgir NI, Naheed A, Luby SP, 2010. Coping strategies for financial burdens in families with childhood pneumonia in Bangladesh. BMC Public Health 10: 622.

21. Ortiz-Rodriguez J, Small E, 2017. The financial burden of healthcare cost: coping strategies for medical expenses in Mexico. Soc Indic Res 133: 275-284.

22. Tahsina $T$ et al., 2018. Determinants of hardship financing in coping with out of pocket payment for care-seeking of underfive children in selected rural areas of Bangladesh. PLoS One 13: e0196237.

23. Buigut S, Ettarh R, Amendah DD, 2015. Catastrophic health expenditure and its determinants in Kenya slum communities. Int $J$ Equity Health 14: 46.

24. Onyeneke RU, Aligbe JO, 2016. Migrants' participation in entrepreneurial activities in Imo State, Nigeria. Int J Migr Resid Mobil 1: 269-282.

25. Lister J, 2005. Globalization and Health System Change: WHO Commission on Social Determinants of Health. Globalization and Health Knowledge Network Research Papers 321: 13. Geneva, Switzerland: World Health Organization.

26. Mberu BU, Mutua M, 2015. Internal migration and early life mortality in Kenya and Nigeria. Popul Space Place 21: 788-808.

27. Afolabi JA, 2010. Analysis of loan repayment among small scale farmers in Oyo State, Nigeria. J Soc Sci 22: 115-119.

28. Adekoya AE, 2009. Food insecurity and coping strategies among rural households in Oyo State, Nigeria. J Food Agric Environ 7: 187-191.

29. Olarinde LO, Okunola A, 2008. Determinants of technical efficiency in bee - keeping farms in Oyo state, Nigeria: a stochastic production frontier approach. Res J Agric Biol Sci 4: 65-69.

30. Adeola GL, Fayomi O, 2012. The political and security implications of cross border migration between Nigeria and her francophone neighbours. Int J Soc Sci Tomorrow 1: 1-9.

31. Vandeyar S, 2010. Educational and socio-cultural experiences of immigrant students in South African schools. Educ Inq 131: 347-365.

32. World Bank, 2012. Education and Migration the Nature of International Migration in MENA.

33. Mast MS, Sieverding M, Esslen M, Graber K, Jäncke L, 2008. Masculinity causes speeding in young men. Accid Anal Prev 40: 840-842.

34. Ilesanmi OS, Adebiyi AO, Fatiregun AA, 2014. National health insurance scheme: how protected are households in Oyo State, Nigeria from catastrophic health expenditure? Int $J$ Health Policy Manag 2: 175-180.

35. Odeyemi I, Nixon J, 2013. Assessing equity in health care through the national health insurance schemes of Nigeria and Ghana: a 
review-based comparative analysis. International Journal for Equity in Health 12: 9.

36. Makinen M et al., 2000. Inequalities in health care use and expenditures: empirical data from eight developing countries and countries in transition. Bull World Health Organ 78 55-65.

37. Badurdeen S, Valladares DB, Farrar J, Gozzer E, Kroeger A, Kuswara N, 2013. Sharing experiences: towards an evidence-based model of dengue surveillance and outbreak response in Latin America and Asia. BMC Public Health 13: 607

38. Mcintyre D, Thiede M, Whitehead M, 2006. What are the economic consequences for households of illness and of paying for health care in low- and middle-income country contexts? Soc Sci Med 62: 858-865.

39. Etiaba E, Onwujekwe O, Uzochukwu B, Adjagba A, 2015. Investigating payment coping mechanisms used for the treatment of uncomplicated malaria to different socio-economic groups in Nigeria. 15: 1-4.

40. Minh Van H, Thi N, Phuong K, Saksena P, James CD, Xu K, 2002. Financial burden of household out-of-pocket health expenditure in Viet Nam: findings from the national living standard survey Soc Sci Med 96: 258-263.

41. Wang $\mathrm{H}$, Zhang L, Hsiao W, 2006. III health and its potential influence on household consumptions in rural China. Health Policy 78: 167-177. 